\title{
ANALISIS RESISTANCE FACTOR DALAM PENERAPAN PEMBELAJARAN BERBASIS ELEKTRONIK MENGGUNAKAN PENDEKATAN HUMAN-CENTERED-APPROACH
}

\author{
Viska Armalina ${ }^{1}$, Wisnu Hera Pamungkas ${ }^{2}$ \\ Dosen Universitas Mulia ${ }^{1,2}$ \\ Jl. Letjend. TNI. Z.A Maulani No. 9 Damai, Bahagia, Balikpapan Kota \\ Sur-el : viskaarmalina@universitasmulia.ac.id ${ }^{1}$, wisnuhera@ universitasmulia.ac.id ${ }^{2}$

\begin{abstract}
E-learning becomes an alternative way to transfer information effectively and efficiently in adopting information technology as a means of teaching and learning. Information technology applied must be Acceptable, if it's not, it will display the behavior of resistance to change. This study uses the Human-Centered Approach-related resistance to change in preparation of the questionnaire instrument and using factor analysis in data processing and analysis. The process of taking samples using simple random sampling technique in which the taking of samples of the population that was randomly without regard to strata that exist in the population. Factor analysis model used is Principal Component Analysis (PCA). Phases of analysis of factors such as the correlation matrix, factor extraction, factor rotation, and interpretation of factors. Results from this research can be concluded that these factors play a role in the emergence of resistance to change in sequence from the most dominant factor Competence Factor, Motivation and Planning Implementation Factors, Communications in Leadership Factor. It would be better if the sampling is not only for teachers but also involves students and
\end{abstract} \\ Factors, Culture Factor, Situations and Conditions Factors, Personality Factors, and Security \\ mapped based on certain criteria which are equipped with the characteristics of each sample.
}

Keywords: information technology, e-learning, factor analysis

\begin{abstract}
Abstrak : E-learning menjadi suatu alternatif untuk mentransfer informasi secara efektif dan efisien dalam mengadopsi teknologi informasi sebagai sarana kegiatan belajar mengajar. Teknologi informasi yang diterapkan tersebut harus bersifat Acceptable, jika tidak, maka akan muncul perilaku penolakan terhadap perubahan (Resistance to change). Penelitian ini menggunakan metode Human-CenteredApproach yang terkait dengan Resistance to change dalam penyusunan instrumen kuesionernya dan menggunakan analisis faktor dalam pengolahan dan analisa data. Proses pengambilan sampelnya menggunakan teknik Simple Random Sampling dimana pengambilan anggota sampel dari populasi yang dilakukan secara acak tanpa memperhatikan strata yang ada dalam populasi. Model analisis faktor yang digunakan adalah Principal Component Analysis (PCA). Tahapan dari analisis faktor antara lain matriks korelasi, ekstraksi faktor, rotasi faktor, dan interpretasi faktor. Hasil dari penelitian ini dapat disimpulkan faktor-faktor yang berperan dalam munculnya Resistance to change secara berurutan dari yang paling dominan adalah Faktor Kompetensi, Faktor Motivasi dan Perencanaan Implementasi, Faktor Komunikasi dengan Pimpinan, Faktor Kultur, Faktor Situasi dan Kondisi, Faktor Kepribadian, dan Faktor Keamanan. Akan lebih baik lagi apabila dalam pengambilan sampel tidak hanya guru tapi juga melibatkan siswa dan dipetakan berdasar kriteria tertentu yang dilengkapi dengan karakteristik masing-masing sampel.
\end{abstract}

Kata kunci: teknologi informasi, e-learning, analisis faktor

\section{PENDAHULUAN}

E-learning menjadi suatu altematif untuk mentransfer informasi secara efektif dan efisien dalam mengadopsi teknologi informasi sebagai sarana kegiatan belajar mengajar. Teknologi informasi yang diterapkan harus bersifat acceptable, jika tidak, maka akan muncul perilaku penolakan terhadap perubahan (Resistance to Change). SMU Muhammadiyah 2 merupakan salah satu sekolah menengah 
yang masih dalam tahap merintis e-Learning. Sarana dan prasarana sekolah dinilai sudah memenuhi syarat untuk penerapan e-Learning secara keseluruhan, namun pada kenyataannya $e$ Learning belum sepenuhnya dapat diterapkan di SMU Muhammadiyah 2. Penelitian ini bertujuan untuk mengetahui faktor yang dominan yang mempengaruhi munculnya resistance to change terhadap penerapan $e$ Learning dalam institusi pendidikan, terutama di SMU Muhammadiyah 2.

Penelitian mengenai e-Learning merupakan ranah bahasan yang masih banyak dibahas oleh peneliti karena keunikannya. Dalam setiap implementasi e-Learning akan ditemukan masalah atau kasus yang tidak ditemui di tempat lain meskipun menggunakan platform aplikasi yang sama. Salah satunya ialah penelitian tentang Risk Assessment and Risk Mitigation of E-Learning yang dilakukan pada Sekolah Menengah Pertama (SMP) oleh Muqtadiroh (2017). Dalam hasil penelitian tersebut dipaparkan dimana salah satu hasilnya adalah adanya faktor unwillingness of the users to change to use e-learning atau keengganan pengguna untuk beralih menggunakan $e$ learning [1].

Dalam bahasan lainnya yang mengambil sudut pandang guru dilakukan oleh Hasanah (2016). Pada penelitian yang dilakukan kepada 60 guru Sekolah Menengah Kejuruan (SMK) didapatkan hasil bahwa sebanyak 29 orang guru yang memiliki persepsi negatif terhadap blended learning, serta sebanyak 31 orang guru memiliki persepsi positif [2].
Keengganan atau resistansi ini dapat pula ditimbulkan dari kurangnya dukungan dari internal sekolah. Seperti yang dipaparkan dalam penelitian terkait Penerapan Learning Management System Dengan Pendekatan QSPM bahwa manajemen perlu untuk menetukan langkah strategis yang perlu dilakukan untuk memastikan keberhasilan implementasi LMS berdasarkan tingkatan prioritas tertentu [3].

Abainya manajemen dalam memahami kompleksitas penerapan e-learning dapat berdampak pada kurang siapnya sumber daya manusia seperti yang dipaparkan dalam penelitian mengenai kesiapan guru sekolah dasar dan menengah di Hong Kong yang dilakukan oleh Swatman (2007), didapatkan hasil bahwa responden belum sepenuhnya siap untuk teknologi e-learning meskipun kebijakan dari pemerintah terkait e-learning telah dipaparkan sejak 2004 [4].

\section{METODOLOGI PENELITIAN}

Penelitian ini menggunakan metode Human-Centered-Approach yang terkait dengan resistance to change, dimana dalam penyusunan instrumen kuesionernya dan menggunakan analisis faktor dalam pengolahan dan analisa data. Data hasil dari kuesioner diolah dan dianalisa menggunakan model Principal Component Analysis (PCA). Hasil keluaran dari analisis faktor akan dianalisa sehingga menghasilkan faktor-faktor yang mempengaruhi munculnya resistance to change dalam penerapan e-Learning. Tahapan inti dari 
penelitian ini yakni pada analisis faktor yang tahapannya dapat dilihat pada Gambar 1.

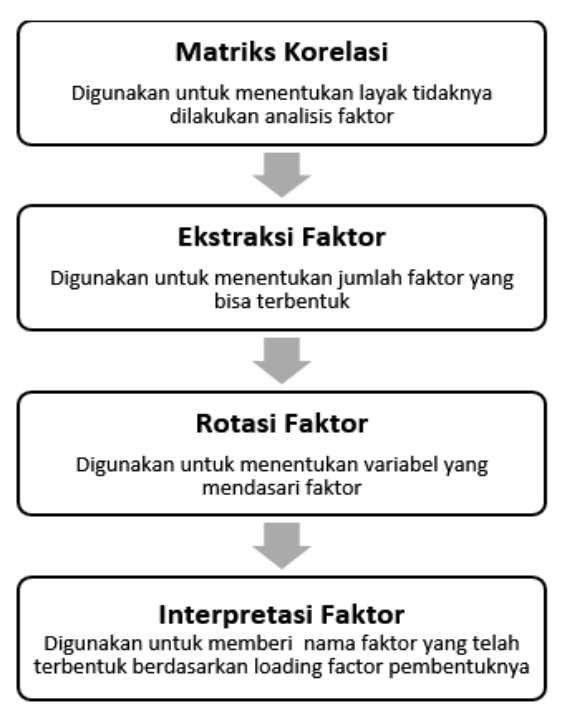

\section{Gambar 1. Tahapan Analisis Faktor}

Analisis Faktor sendiri adalah pendekatan statistik yang dapat digunakan untuk menganalisis interrelationship sejumlah variabel dan untuk menjelaskan dimensi-dimensi (yang disebut dengan faktor) yang melandasi variabel tersebut. Terdapat 2 (dua) metode dasar dalam analisis faktor yaitu principal component analysis (PCA) dan common factor analysis (CFA) [5].

PCA menggunakan total varians dalam analisisnya. $C F A$ mengekstrak faktor hanya berdasarkan common variance. Dalam penentuan jumlah faktor yang valid didasarkan antara lain pada :

1. Kebutuhan sendiri

2. Eigenvalue : Faktor yang memiliki nilai eigenvalue lebih dari 1 (satu) dianggap valid. Sebaliknya faktor yang memiliki nilai kurang dari 1 (satu) dianggap tidak valid.
3. Scree plot : Dengan scree plot dapat terlihat pola penurunan eigenvalue. Jika setelah sebuah faktor mengalami penurunan tajam maka faktor yang valid hanya sampai faktor tersebut.

4. Prosentase varians yang dijelaskan

5. Teknik belah tengah

\subsection{Matriks Korelasi}

Proses analisis didasarkan pada suatu matriks korelasi. Agar analisis faktor dapat digunakan secara tepat maka variabel-variabel yang akan dianalisis harus berkorelasi. Apabila koefisien korelasi antar variabel terlalu kecil, hubungan lemah maka analisis faktor tidak tepat. Selain terdapat korelasi antara variabel asli, juga diharapkan berkorelasi dengan faktor sebagai variabel baru yang disaring dari variabel asli. Statistik formal yang tersedia untuk menguji ketepatan model faktor adalah Bartlett Test dan KMO (Kaiser-Mayer-Olkin) [6].

\subsection{Ekstraksi Faktor}

Ekstraksi faktor digunakan untuk menentukan jumlah faktor yang terbentuk. Beberapa prosedur yang dapat digunakan untuk menetukan jumlah faktor adalah dengan cara penentuan secara apriori yaitu ditentukan secara langsung atau berdasarkan parameter eigenvalue, scree plot, percentage of variance, split-half reliability dan significance test [7].

\subsection{Rotasi Faktor}

Hasil dari analisis faktor adalah matriks faktor pola (factor pattern matrix) yaitu matriks 
faktor yang memuat atau berisi koefisien yang dipergunakan untuk mengekspresikan variabel baku yang dinyatakan dalam faktor. Koefisien ini yang disebut dengan muatan faktor (loading factor) yaitu koefisien yang mewakili korelasi antar faktor dan variabel. Koefisien dari matriks faktor ini yang digunakan dalam menginterpretasikan faktor.

Akan tetapi, koefisien matriks faktor yang belum dirotasi, jarang menghasilkan faktor yang bisa diinterpretasikan karena faktor-faktor tersebut berkorelasi dengan lebih dari satu variabel. Maka matriks faktor perlu dilakukan rotasi diubah menjadi matriks yang lebih sederhana, lebih menegaskan korelasi antara satu faktor dengan satu variabel sehingga lebih mudah diinterpretasikan [7].

\subsection{Interpretasi Faktor}

Setelah diperoleh sejumlah faktor yang valid, selanjutnya adalah menginterpretasikan nama faktor. Mengingat faktor merupakan sebuah konstruk dan sebuah konstruk akan memiliki makna apabila diartikan.

Interpretasi faktor dapat dilakukan dengan mengetahui variabel-variabel yang membentuknya. Interpretasi nama faktor didasarkan pada variabel apa yang diwakilinya. Interpretasi dilakukan dengan judgement akan tetapi masih disesuaikan dengan kaidah-kaidah teori yang berlaku.

\section{HASIL DAN PEMBAHASAN}

Penelitian dilakukan dengan menyebarkan kuesioner langsung ke guru-guru SMU Muhammadiyah 2 sebagai responden penelitian Hasil kuesioner yang terkumpul berjumlah 42 kuesioner dari 60 kuesioner yang disebar. Kemudian agar lebih menguatkan lagi, maka dilakukan uji validitas dan reliabilitas pada kuesioner ini. Dengan menggunakan taraf signifikansi 95\% dan 99\%, maka didapat r-tabel 0,304 untuk taraf signifikansi $95 \%$ dan 0,393 untuk taraf signifikansi $99 \%$.

Tabel 1. Hasil Uji Validitas Akhir

\begin{tabular}{cccccc}
\hline $\begin{array}{c}\text { Variabel } \\
\text { Soal }\end{array}$ & Total & Keterangan & $\begin{array}{c}\text { Variabel } \\
\text { soal }\end{array}$ & Total & Keterangan \\
\hline a1 & 0.555 & Valid & $\mathrm{d} 3$ & 0.662 & Valid \\
a2 & 0.484 & Valid & $\mathrm{d} 4$ & 0.409 & Valid \\
a3 & 0.580 & Valid & $\mathrm{d} 5$ & 0.437 & Valid \\
a4 & 0.504 & Valid & $\mathrm{d} 6$ & 0.558 & Valid \\
a5 & 0.641 & Valid & $\mathrm{e} 1$ & 0.702 & Valid \\
a6 & 0.558 & Valid & $\mathrm{e} 2$ & 0.681 & Valid \\
a7 & 0.622 & Valid & $\mathrm{e} 3$ & 0.604 & Valid \\
a8 & 0.525 & Valid & $\mathrm{e} 4$ & 0.753 & Valid \\
b1 & 0.545 & Valid & $\mathrm{f} 1$ & 0.211 & Tidak \\
b2 & 0.304 & Tidak & $\mathrm{f} 2$ & 0.028 & Tidak \\
b3 & 0.710 & Valid & $\mathrm{g} 1$ & 0.550 & Valid \\
b4 & 0.575 & Valid & $\mathrm{g} 2$ & 0.007 & Tidak \\
c1 & 0.592 & Valid & $\mathrm{g} 3$ & 0.671 & Valid \\
c2 & 0.558 & Valid & $\mathrm{g} 4$ & -0.300 & Tidak \\
c3 & 0.138 & Tidak & $\mathrm{h} 1$ & 0.484 & Valid \\
c4 & 0.532 & Valid & $\mathrm{h} 2$ & 0.522 & Valid \\
c5 & 0.449 & Valid & $\mathrm{h} 3$ & 0.659 & Valid \\
d1 & 0.530 & Valid & $\mathrm{i} 1$ & 0.459 & Valid \\
d2 & 0.590 & Valid & $\mathrm{i} 2$ & 0.538 & Valid \\
\hline
\end{tabular}

Sementara dari uji reliabilitas diperoleh nilai alpha cronbach sebesar 0,911 yang berarti dapat dinyatakan reliabel karena nilainya lebih dari ambang batas yaitu 0,600 .

Tabel 2. Hasil Uji Reliabilitas Akhir

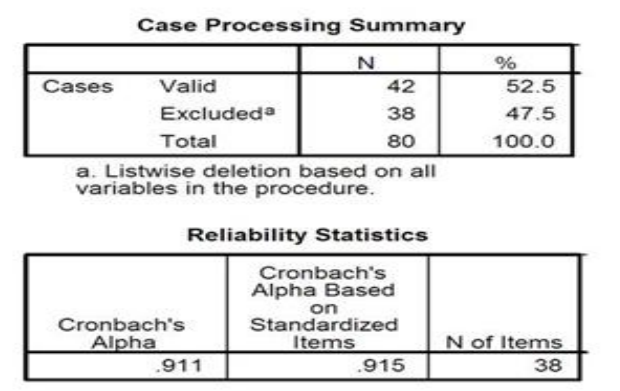


Untuk menguji apakah analisis faktor layak dilakukan dapat dilihat $K M O$ and Bartlett's Test.

Tabel 3. Hasil KMO and Bartlett's Test Akhir

\begin{tabular}{|l|r|}
\hline \multicolumn{2}{c}{ KMO and Bartlett's Test } \\
\begin{tabular}{|c|r|r|}
\hline Kaiser-Meyer-Olkin Measure of Sampling Adequacy. & .701 \\
Bartlett's Test of Sphericity $\quad$ Approx. Chi-Square & 766.127 \\
& df & 325 \\
Sig. & .000 \\
\hline
\end{tabular}
\end{tabular}

Communalities menunjukkan berapa varians yang dapat dijelaskan oleh faktor yang diekstrak. Setiap variabel berkorelasi dengan variabel yang diekstrak.

Tabel 4. Communalities

\begin{tabular}{|c|c|c|c|c|c|}
\hline \multicolumn{3}{|c|}{ Comm unal ities } & & & \\
\hline & Initial & Extraction & & & \\
\hline a1 & 1.000 & .831 & & & \\
\hline 32 & 1.000 & .855 & & & \\
\hline$a 3$ & 1.000 & .727 & $\mathrm{~d} 2$ & 1.000 & \\
\hline 34 & 1.000 & 576 & 63 & 1000 & \\
\hline 35 & 1.000 & .845 & do & 1.000 & .805 \\
\hline 36 & 1.000 & .784 & $=1$ & 1.000 & .795 \\
\hline 37 & 1.000 & .848 & $=2$ & 1.000 & .789 \\
\hline 38 & 1.000 & .728 & $=3$ & 1.000 & .856 \\
\hline b1 & 1.000 & .794 & $=4$ & 1.000 & .783 \\
\hline b3 3 & 1.000 & .776 & $b_{3}$ & 1.000 & .755 \\
\hline b4 & 1.000 & .848 & h1 & 1.000 & .876 \\
\hline$c 1$ & 1.000 & .772 & h2 & 1.000 & .749 \\
\hline 0.2 & 1.000 & .742 & h3 & 1.000 & .805 \\
\hline 04 & 1.000 & .697 & & & \\
\hline 05 & 1.000 & 830 & & & \\
\hline
\end{tabular}

Tabel 5. Total Variance Explained

\begin{tabular}{|c|c|c|c|c|c|c|c|c|c|}
\hline \multirow[b]{2}{*}{ Component } & \multicolumn{3}{|c|}{ Initial Eiqenvalues } & \multicolumn{3}{|c|}{$\begin{array}{c}\text { Extraction Sums of Squared } \\
\text { Loadinqs }\end{array}$} & \multicolumn{3}{|c|}{$\begin{array}{l}\text { Rotation Sums of Squared } \\
\text { Loadings }\end{array}$} \\
\hline & Total & \begin{tabular}{|c|}
$\%$ of \\
Variance
\end{tabular} & $\underset{\%}{\text { Cumulative }}$ & Total & \begin{tabular}{|c|}
$\%$ of \\
Variance
\end{tabular} & $\underset{\%}{\text { Cumulative }}$ & Total $\mid$ & \begin{tabular}{|c|}
$\%$ of \\
Variance
\end{tabular} & $\underset{\%}{\text { Cumulative }}$ \\
\hline 1 & 10.252 & 39.431 & 39.431 & 10.252 & 39.431 & 39.431 & 4.825 & 18.559 & 18.559 \\
\hline $2^{2}$ & $\mid 3.114$ & 11.977 & 51.408 & \begin{tabular}{|l|}
3.114 \\
\end{tabular} & 11.977 & 51.408 & 3.369 & 12.957 & 31.516 \\
\hline 3 & 1.920 & 7.383 & 58.791 & 1.920 & 7.383 & 58.791 & 2.957 & 11.373 & 42.889 \\
\hline 4 & 1.424 & 5.478 & 64.269 & \begin{tabular}{|c|}
1.424 \\
\end{tabular} & 5.478 & 64.269 & 2.488 & 9.571 & 52.460 \\
\hline 5 & 1.313 & 5.048 & 69.317 & $\mid 1.313$ & 5.048 & 69.317 & 2.470 & 9.499 & 61.959 \\
\hline 6 & 1.123 & 4.318 & 73.636 & 1.123 & 4.318 & 73.636 & 2.399 & 9.228 & 71.187 \\
\hline 7 & 1.020 & 3.925 & 77.561 & \begin{tabular}{|c|}
1.020 \\
\end{tabular} & 3.925 & 77.561 & 1.657 & 6.374 & 77.561 \\
\hline 8 & .828 & 3.186 & 80.747 & & & & & & \\
\hline 9 & 683 & 2.627 & 83.374 & & & & & & \\
\hline 10 & .637 & 2.451 & 85.825 & & & & & & \\
\hline 11 & .600 & 2.309 & 88.133 & & & & & & \\
\hline 12 & .498 & 1.916 & 90.049 & & & & & & \\
\hline 13 & .465 & 1.789 & 91.838 & & & & & & \\
\hline 14 & .350 & 1.345 & 93.184 & & & & & & \\
\hline 15 & 316 & 1.214 & 94.398 & & & & & & \\
\hline 16 & 267 & 1.028 & 95.426 & & & & & & \\
\hline 17 & 234 & .898 & 96.324 & & & & & & \\
\hline 18 & 195 & .751 & 97.075 & & & & & & \\
\hline 19 & .189 & .726 & 97.801 & & & & & & \\
\hline 20 & 163 & .626 & 98.427 & & & & & & \\
\hline 21 & .114 & 439 & 98.866 & & & & & & \\
\hline 22 & .103 & 398 & 99.264 & & & & & & \\
\hline 23 & .066 & 252 & 99.516 & & & & & & \\
\hline 24 & .061 & .235 & 99.751 & & & & & & \\
\hline 25 & .042 & .161 & 99.912 & & & & & & \\
\hline 26 & .023 & 088 & 100.000 & & & & & & \\
\hline
\end{tabular}

Dari Tabel 5, terlihat faktor yang terbentuk sebanyak 7 (tujuh) faktor berdasarkan nilai eigenvalue lebih dari 1 dengan total varian yang menunjukkan keragaman yang dapat dijelaskan oleh ketujuh faktor tersebut sebesar $77,561 \%$ sedangkan $22,439 \%$ sisanya merupakan faktor unik yang tidak dapat diwakili oleh delapan faktor tersebut.

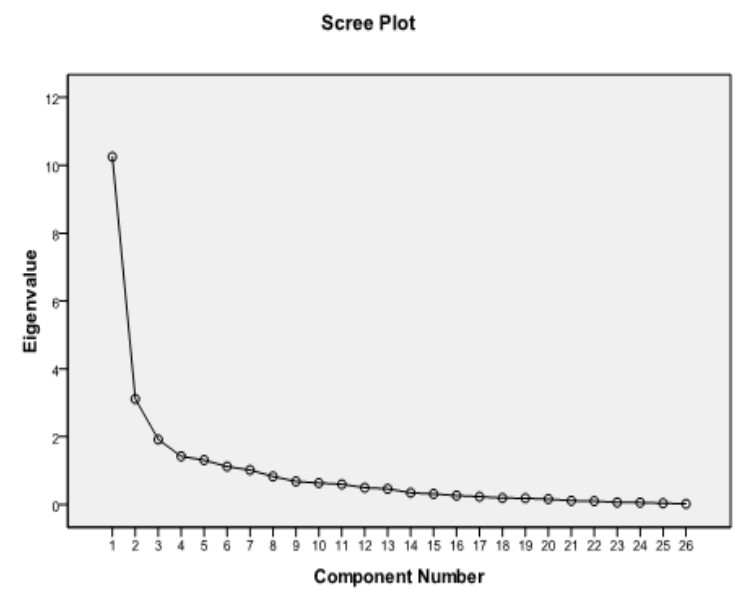

Gambar 2. Scree Plot

Output yang paling penting dari analisis faktor adalah matriks faktor. Matriks ini berisi koefisien yang disebut juga loading factor yang menjelaskan korelasi antara faktor dengan variable. Loading factor menunjukkan besarnya korelasi antara setiap variabel dengan ketujuh faktor yang terbentuk. Penentuan variabel yang melandasi atau membentuk suatu faktor dilakukan dengan cara membandingkan besarnya factor loading satu variabel dengan setiap faktor [8]. Nilai loading factor lebih dari 0,50 menunjukkan korelasi yang kuat sehingga merupakan kandidat variabel tersebut melandasi faktor yang berkorelasi. 
Tabel 6. Matriks Faktor

\begin{tabular}{|c|c|c|c|c|c|c|c|}
\hline \multicolumn{8}{|c|}{ Component Matrix" } \\
\hline & \multicolumn{7}{|c|}{ Component } \\
\hline & 1 & 2 & 3 & 4 & 5 & 6 & 7 \\
\hline a1 & .683 & -.518 & .015 & .155 & .052 & -.279 & .135 \\
\hline$a 2$ & .553 & -.512 & .110 & .418 & .119 & .087 & -285 \\
\hline a3 & .631 & -.328 & -.010 & .438 & .085 & .098 & .119 \\
\hline a4 & .587 & -.285 & -184 & -.086 & .114 & .124 & .307 \\
\hline a5 & .767 & -.284 & -.033 & -184 & .073 & -.380 & .051 \\
\hline a6 & .645 & -.423 & .237 & -1131 & .149 & .305 & -.016 \\
\hline a7 & .750 & -.230 & -191 & -251 & .197 & -.251 & .173 \\
\hline a8 & .530 & .240 & .490 & .046 & 276 & -133 & -232 \\
\hline b1 & .581 & .127 & -289 & .454 & -.249 & -.149 & .278 \\
\hline b3 & .738 & .000 & .309 & -283 & .102 & .214 & -.050 \\
\hline b4 & .560 & .307 & .013 & .128 & -.520 & .237 & -.302 \\
\hline$c 1$ & .539 & .291 & .449 & .058 & .102 & .326 & .278 \\
\hline$c 2$ & .500 & .584 & .176 & -203 & -.002 & -131 & .292 \\
\hline 04 & .511 & .602 & .200 & .043 & -.055 & -.158 & .057 \\
\hline .5 & .405 & .558 & .438 & 270 & .107 & -.273 & -.080 \\
\hline$d 2$ & .636 & -.120 & -.072 & -.095 & -321 & .382 & .283 \\
\hline d3 & .054 & .259 & .129 & -133 & -.447 & -055 & .081 \\
\hline d6 & .429 & .407 & -331 & .469 & 283 & .202 & .071 \\
\hline e1 & .813 & -146 & .087 & -275 & .070 & -008 & -.138 \\
\hline$e 2$ & .758 & -.218 & -143 & -219 & -318 & -.031 & -.004 \\
\hline$e 3$ & .655 & -.121 & -164 & .115 & -205 & -.342 & -.112 \\
\hline$=4$ & .807 & -105 & .069 & -.075 & 258 & .155 & -.139 \\
\hline$g^{3}$ & .728 & -.222 & .109 & .168 & -.240 & .028 & -278 \\
\hline h1 & .500 & .307 & -.588 & -151 & .110 & .078 & -372 \\
\hline h2 & .524 & .489 & -380 & -225 & .113 & .042 & -.100 \\
\hline h3 & .600 & .386 & $\mid-464$ & .041 & 288 & .073 & .080 \\
\hline
\end{tabular}

a. 7 components extracted.

Hasil dari matriks faktor di atas berarti belum dapat digunakan untuk menginterpretasikan faktor yang terbentuk dan variabel yang melandasinya karena masih terdapat masalah seperti faktor yang tidak memiliki variabel yang melandasi dan variabel yang tidak memiliki korelasi. Untuk dapat menyelesaikan masalah tersebut maka matriks faktor perlu dilakukan rotasi.

Rotasi faktor dilakukan untuk lebih menegaskan korelasi antara satu faktor dengan satu variabel sehingga lebih mudah diinterpretasikan Jadi setelah dilakukan rotasi faktor diharapkan setiap variabel memiliki korelasi yang signifikan dengan hanya salah satu faktor dan setiap faktor memiliki minimal 1 (satu) variabel yang melandasinya. Sehingga dari matriks faktor yang telah dirotasi akan dapat dilakukan interpretasi faktor dengan tepat.

Rotasi yang digunakan dalam penelitian ini adalah secara orthogonal rotation dengan metode varimax. Metode Varimax merupakan metode yang berusaha meminimumkan banyaknya variabel dengan high loading pada satu faktor, dengan demikian memudahkan pembuatan interpretasi mengenai faktor [9].

Tabel 7. Matriks Rotasi Faktor

\begin{tabular}{|c|c|c|c|c|c|c|c|}
\hline \multicolumn{8}{|c|}{ Rotated Com ponent Matrix } \\
\hline & \multicolumn{7}{|c|}{ Component } \\
\hline & 1 & 2 & 3 & 4 & 5 & 6 & 7 \\
\hline a1 & .758 & .035 & -.104 & .133 & .045 & .398 & .250 \\
\hline 32 & .340 & -.001 & -.022 & .137 & .095 & .833 & .130 \\
\hline a3 & .381 & .057 & .032 & 287 & .078 & .543 & .456 \\
\hline a4 & .500 & -.083 & .179 & .454 & .019 & .099 & .287 \\
\hline a5 & .859 & .194 & .134 & .115 & .118 & .154 & .030 \\
\hline 36 & .420 & .038 & .007 & .626 & .097 & .438 & -.116 \\
\hline a7 & .830 & .093 & .282 & 245 & -.004 & .053 & .091 \\
\hline a8 & .188 & .726 & .102 & .131 & .018 & .331 & -.100 \\
\hline b1 & .302 & .177 & .177 & -.022 & 338 & .092 & .720 \\
\hline b3 & .387 & .375 & .178 & .580 & 228 & .203 & -203 \\
\hline$b 4$ & -.047 & .253 & .288 & .117 & .805 & .202 & .095 \\
\hline c1 & -.010 & .577 & .020 & .626 & .115 & .075 & .171 \\
\hline$c_{2}$ & .210 & .649 & .218 & 238 & .168 & -380 & .123 \\
\hline 04 & .094 & .716 & .242 & .057 & 271 & -.119 & .100 \\
\hline$\infty 5$ & .006 & .882 & .072 & -.087 & .085 & .117 & .133 \\
\hline$d 2$ & .290 & -.086 & .100 & .603 & .480 & .017 & .263 \\
\hline$d 3$ & .318 & .392 & .095 & 200 & .641 & -.112 & .098 \\
\hline 16 & -.110 & .257 & .592 & .117 & -045 & .217 & .560 \\
\hline e1 & .644 & .255 & .249 & 323 & 248 & .245 & -.180 \\
\hline$=2$ & .633 & -.023 & .176 & 282 & .526 & .097 & .048 \\
\hline$=3$ & .591 & .135 & .168 & -138 & 378 & .237 & .207 \\
\hline$=4$ & .445 & .262 & .354 & .447 & .110 & .417 & -.048 \\
\hline$g^{3}$ & .398 & .157 & .071 & .155 & .511 & .528 & .080 \\
\hline h1 & .188 & .000 & .883 & -.031 & 233 & .074 & -.028 \\
\hline h2 & .170 & .248 & .770 & .084 & 208 & -.128 & .000 \\
\hline h3 & .230 & .202 & .752 & .179 & .001 & -.004 & .338 \\
\hline
\end{tabular}

Setelah diperoleh sejumlah faktor yang valid, selanjutnya adalah menginterpretasikan nama faktor. Interpretasi nama faktor didasarkan pada variabel apa yang diwakilinya. Interpretasi dilakukan dengan judgement akan tetapi masih disesuaikan dengan kaidah-kaidah teori yang berlaku [10]. 
Tabel 8. Interpretasi Faktor - Faktor Kompetensi

\begin{tabular}{lc}
\hline \multicolumn{1}{c}{ Variabel yang melandasi } & Loading Factor \\
\hline $\begin{array}{l}\text { Penerapan e-learning hanya } \\
\text { akan membuang tenaga dan } \\
\text { waktu }\end{array}$ & 0,859 \\
$\begin{array}{l}\text { E-learning tidak penting } \\
\text { untuk diterapkan }\end{array}$ & 0,830 \\
$\begin{array}{l}\text { E-learning tidak pasti hasilnya } \\
\text { E-learning bukan strategi } \\
\text { pembelajaran yang tepat dan } \\
\text { tidak sesuai kurikulum }\end{array}$ & 0,758 \\
$\begin{array}{l}\text { Kurikulum yang ada sudah } \\
\text { terlalu padat }\end{array}$ & 0,644 \\
$\begin{array}{l}\text { Adanya persaingan dengan } \\
\text { sekolah SBI lainnya }\end{array}$ & 0,533 \\
$\begin{array}{l}\text { Guru merasa lebih nyaman } \\
\text { dengan metode konvensional }\end{array}$ & 0,500 \\
\hline
\end{tabular}

Tabel 9. Interpretasi Faktor - Faktor Motivasi dan Perencanaan Implementasi

\begin{tabular}{|c|c|}
\hline Variabel yang melandasi & Loading Factor \\
\hline $\begin{array}{l}\text { Guru yang } r \text { telah } \\
\text { menerapkan } \\
\text { cenderung } \text { e-learning } \\
\text { pintar daripada yang belum }\end{array}$ & 0,882 \\
\hline $\begin{array}{l}\text { Guru yang telah } \\
\text { menerapkan e-learning } \\
\text { cenderung merasa lebih } \\
\text { pintar daripada yang belum }\end{array}$ & 0,726 \\
\hline $\begin{array}{l}\text { Guru tidak menyukai kritik } \\
\text { dari orang lain }\end{array}$ & 0,716 \\
\hline $\begin{array}{l}\text { Kurangnya pelatihan bagi } \\
\text { guru }\end{array}$ & 0,649 \\
\hline $\begin{array}{l}\text { Tidak ada fasilitas yang } \\
\text { mendukung penerapan } e- \\
\text { learning }\end{array}$ & 0,577 \\
\hline
\end{tabular}

Tabel 10. Interpretasi Faktor - Faktor Komunikasi dengan Pimpinan

\begin{tabular}{lc}
\hline Variabel yang melandasi & Loading Factor \\
\hline $\begin{array}{l}\text { Pimpinan tidak mau tahu } \\
\text { bagaimana metode } \\
\text { pengajaran oleh guru }\end{array}$ & 0,883 \\
Pimpinan tidak mengerti \\
masalah yang dihadapi guru \\
Tidak ada keterbukaan \\
antara guru dengan \\
pimpinan 0,770 \\
Adanya gap diantara guru \\
\hline
\end{tabular}

Tabel 11. Interpretasi Faktor - Faktor Keamanan

\begin{tabular}{lc}
\hline \multicolumn{1}{c}{ Variabel yang melandasi } & Loading Factor \\
\hline $\begin{array}{l}\text { Guru tidak ingin mempelajari } \\
e \text {-learning }\end{array}$ & 0,720 \\
Adanya gap diantara guru & 0,560 \\
\hline
\end{tabular}

Tabel 12. Interpretasi Faktor - Faktor Kultur

\begin{tabular}{|c|c|}
\hline Variabel yang melandasi & Loading Factor \\
\hline $\begin{array}{l}\text { Guru tidak siap dengan } \\
\text { penerapan } e \text {-learning }\end{array}$ & 0,626 \\
\hline $\begin{array}{l}\text { Tidak ada fasilitas yang } \\
\text { mendukung penerapan } e- \\
\text { learning }\end{array}$ & 0,626 \\
\hline $\begin{array}{l}\text { Guru merasa lebih nyaman } \\
\text { dengan metode konvensional }\end{array}$ & 0,603 \\
\hline $\begin{array}{l}\text { E-learning } \\
\text { sebagai sesuatu yang sulit } \\
\text { dan rumit }\end{array}$ & 0,580 \\
\hline
\end{tabular}

Tabel 13. Interpretasi Faktor - Faktor Situasi dan Kondisi

\begin{tabular}{lc}
\hline Variabel yang melandasi & Loading Factor \\
\hline $\begin{array}{l}\text { E-learning dipandang perlu } \\
\text { untuk mata pelajaran }\end{array}$ & 0,641 \\
tertentu saja & \\
$\begin{array}{l}\text { Kurikulum yang ada sudah } \\
\text { terlalu padat }\end{array}$ & 0,526 \\
$\begin{array}{l}\text { Guru baru belum berani } \\
\text { menerapkan e-learning }\end{array}$ & 0,511 \\
\hline
\end{tabular}

Tabel 14. Interpretasi Faktor - Faktor Kepribadian

\begin{tabular}{|c|c|}
\hline Variabel yang melandasi & Loading Factor \\
\hline $\begin{array}{l}\text { Guru tidak percaya diri } \\
\text { menerapkan e-learning }\end{array}$ & 0,833 \\
\hline $\begin{array}{l}\text { Guru tidak yakin dengan } \\
\text { kemampuan siswa terhadap } \\
\text { e-learning }\end{array}$ & 0,543 \\
\hline $\begin{array}{l}\text { Guru baru belum berani } \\
\text { menerapkan } \text { e-learning }\end{array}$ & 0,528 \\
\hline
\end{tabular}

Tabel 15. Hubungan teori Resistance To Change dan faktor yang terbentuk

\begin{tabular}{|c|c|}
\hline $\begin{array}{c}\text { Aspek Teori Resistance } \\
\text { to Change }\end{array}$ & Faktor \\
\hline $\begin{array}{l}\text { Indequate understanding } \\
\text { of need for change }\end{array}$ & $\begin{array}{l}\text { Faktor kompetensi } \\
\text { Faktor } \\
\text { situasi/kondisi }\end{array}$ \\
\hline $\begin{array}{l}\text { Poor implementation } \\
\text { efforts }\end{array}$ & $\begin{array}{l}\text { Faktor motivasi dan } \\
\text { perencanaan } \\
\text { implementasi }\end{array}$ \\
\hline $\begin{array}{l}\text { Labor management } \\
\text { relations }\end{array}$ & $\begin{array}{l}\text { Faktor komunikasi } \\
\text { dengan pimpinan }\end{array}$ \\
\hline $\begin{array}{l}\text { A resistance } \\
\text { organizational culture }\end{array}$ & Faktor kultur \\
\hline $\begin{array}{l}\text { Fear of personal inability } \\
\text { to handle new } \\
\text { requirements }\end{array}$ & Faktor kepribadian \\
\hline Security & Faktor keamanan \\
\hline
\end{tabular}




\section{KESIMPULAN}

\section{DAFTAR PUSTAKA}

Faktor-faktor yang berperan dalam munculnya resistance to change secara berurutan adalah Faktor Kompetensi dengan nilai persentase varian sebesar 39,431\%, Faktor Motivasi dan Perencanaan Implementasi dengan nilai persentase varian sebesar $11,977 \%$, Faktor Komunikasi dengan Pimpinan dengan nilai persentase varian sebesar 7,383\%, Faktor Kultur dengan nilai persentase varian sebesar $5,478 \%$, Faktor Situasi dan Kondisi dengan nilai persentase varian sebesar 5,048\%, Faktor Kepribadian dengan nilai persentase 4,318\%, dan Faktor Keamanan dengan nilai persentase $3,925 \%$.

Saran untuk penelitian selanjutnya, lebih baik jika dilakukan analisis faktor yang berperan dalam munculnya resistance to change dalam penerapan e-learning tidak hanya mengambil sampel guru saja, tetapi juga siswa, agar bisa dilihat apakah ada perbedaan persepsi antara guru dengan siswa terkait dengan penerapan elearning sehingga hasilnya akan lebih maksimal. Dalam pengambilan sampel sebaiknya sampel dipetakan berdasar karakteristik atau kriteria tertentu dan dilengkapi dengan informasi mengenai karakteristik masing-masing sampel.

\section{UCAPAN TERIMA KASIH}

Direktorat Riset dan Pengabdian Masyarakat Direktorat Jenderal Penguatan Riset dan Pengembangan Kementerian Riset, Teknologi, dan Pendidikan Tinggi sesuai dengan Kontrak Penelitian Tahun Anggaran 2020.
[1] F.A. Muqtadiroh, E.W.T. Darmaningrat, R.N. Savira. "Risk Assessment and Risk Mitigation of E-Learning Implementation in The Middle School using Failure Modes and Effects Analysis (FMEA)". Prosiding Seminar Nasional Teknologi Informasi, Komunikasi dan Industri (SNTIKI). 2017.

[2] R. Hasanah, F.D. Anggraeni. "Gambaran Persepsi Guru Terhadap Blended Learning". Jurnal Pemikiran \& Penelitian Psikologi (PSIKOLOGIA) Vol. 11, No. 3, hal.129-134. 2016.

[3] W.H. Pamungkas, V. Armalina. "Analisis Penerapan Learning Management System Dengan Pendekatan Quantitative Strategic Planning Matrix". Metik Jurnal, Vol.1. 2017

[4] P.M.C. Swatman dan K.K.T. So. "ELearning Readiness in the Classroom: a Study of Hong Kong Primary and Secondary Teachers". 2007.

[5] B. Simamora. "Analisis Multivariat Pemasaran". Gramedia Pustaka Utama, Jakarta. 2005.

[6] J. Supranto. "Analisis Multivariat Arti \& Interpretasi". Jakarta: PT Rineka Cipta. 2004.

[7] T. Wijaya, "Analisis Data Penelitian Menggunakan SPSS". Penerbit Universitas Atmajaya.Yogyakarta. 2009.

[8] Gudono. Analisis Data Multivariat. Yogyakarta: Penerbit BPFE. 2012.

[9] R.A. Johnson, D.W. Wichern. "Applied Multivariate Statistical Analysis". FifthEdition. New Jersey: Prentice Hall Inc. 2002.

[10] A. Widarjono, "Analisis Statistika Multivariat Terapan". Yogyakarta:Penerbit dan Percetakan Sekolah Tinggi Ilmu Manajemen YKPN. 2010. 